\title{
$\stackrel{\bullet}{\bullet}$ \\ Significance of Spirituality and Health Care: \\ A Holistic Approach
}

IJCRR

Section: Healthcare

ISI Impact Factor

(2019-20): 1.628

IC Value (2019): 90.81

\section{Aruna Dhamija}

$\operatorname{SJIF}(2020)=7.893$

Professor, GLA University, Mathura, Uttar Pradesh, India.

(c) (i) (8)

Copyright@IJCRR

\section{ABSTRACT}

Spirituality plays a vital role in the workplace which directly impact on the health status of employees. Taking care of health in every profession is a threat due to competition, expectations and new challenges in an organization an employee's faces. Managing the work along with spirituality could bear the consequences come on the health of employees. Employee's health status depends on how much the individual is spiritually connected and working with that state of mind at the workplace. The attempt made in this paper is to focus on the ways of improving the spiritual health of employees at the workplace and to recover from tough times. The purpose of this have a look at is while spiritually health care is taken it ends in try for a kingdom of harmony with others whilst running to balance inner wishes and with the relaxation of the world. The Present study will facilitate to understand the essentials required to grow spiritually and enhance non-secular health through Silence, Discussion on Spirituality, Probing and Inquisitive, Willing to Forgive and Be Cheerful. The effect of the current study is that the spirituality assists in understanding diseases and decision to hunt mental support as well as spirituality play an integral role in the holistic care of employees working in the organization.

Key Words: Spirituality, Healthcare, Workplace, Relaxation, Health Status, Mental Support

\section{INTRODUCTION}

Spirituality alludes thereto centre estimation of you this is your deepest self that offers with a significant vibe of which you're, where you originated from, where you're going and the way you will probably arrive at your goal. Spiritual health or wellness appropriately being played out a pivotal capacity in presence; anyway, its significance is stronger than one may furthermore concur with. Spirituality wellbeing may likewise recommend various issues to uncommon people. ${ }^{1}$ For a few, Spirituality may likewise be equivalent with traditional religion, simultaneously concerning others it relates when all is said in done to the standard of private connections or love for nature. An essential reason for strict wellbeing may likewise be the experience that presence is critical and you have watched your private home in it.

Studies have proven that spiritually strong individuals their health condition is better than who don't have trust towards God. Spiritual wellness can be achieved physically and mentally that depend on one's morals, attitude, and purpose. The spiritual as a dimension is the commitment to one's value system. It draws upon the sources that inspire and uplift you and tie timelessly towards truths of humanity. The three different aspects of seeing life are facilitating, setting up, and serving. When one facilitate, life is considered weak. When fix, life taken as broken. While one serve's life becomes whole. Fixing and encouraging can be crafted by the sense of self, and supplier the artistic creations of the spirit. ${ }^{2}$

In an intriguing investigation at the job of Spirituality in wellness care, creator ${ }^{3}$ noticed that the technological advances of the past century tended to change the focus of medicine from a caring, service-oriented model to a technological, cure-oriented model. Spirituality - the more extensive of the two terms - might be characterized as an affectability or connection to non-common or different qualities that encourage somebody advantage observation, self-know-how, and an uplifted skill of presence. The search for meaning and purpose in human existence is to live healthy and few things that require Zero talent such as work ethics, passion, positive attitude and effort. Life has plenty of opportunity for the ones who want to remain healthy. In each tough situation connect

\section{Corresponding Author:}

Aruna Dhamija, Professor, GLA University, Mathura, Uttar Pradesh, India. Ph: +91-8006644202,0000-0001-8825-7414; Email: aruna.dhamija@gla.ac.in

ISSN: 2231-2196 (Print)

Received: 25.08 .2020
ISSN: 0975-5241 (Online)

Revised: 14.10 .2020
Accepted: 11.11 .2020

Published: 16.02 .2021 
towards God and with a constant positive attachment will bring deep internal change and progress in life.

Spirituality is vital to whole or all-encompassing, care in that it assists with managing individuals' know-how of battling and adjust. Profound viewpoints and practices can offer a setting wherein nerves about physical and mental working could likewise be confronted, felt, and comprehended. A dynamically building group of exploration shows that Spirituality and strict practices help wellness. Wellbeing is portrayed today inside the elements of considerations, edge, and soul. ${ }^{4}$ Remembered for those measurements is in essence, mental, enthusiastic, sexual, social and non-mainstream wellness. We can't have generally speaking wellbeing if we overlook any one of these measurements. A considerable lot of the practices related to prosperity are key added substances of a solid non-common life. Models incorporate volunteerism, social duty, good faith, adding to society, connectedness with others, the sentiment of having a place/being a piece of a gathering and love of self/cause to fear for self.

Seeking Spirituality in one's understanding is to discover spirituality for oneself and how it can play an important role in your life. Proper awareness and knowledge will provide hints to enhance your spiritual well-being. ${ }^{5}$ It will offer the answer for some inquiry one if confronting disarrays in their ways of life. It will assist with finding suitable reaction of numerous hard inquiries alongside what offers your life which means and cause, what offers you want, how might one get through difficult stretches, wherein have you at any point discovered solace, what are your most noteworthy examinations, on the off chance that you have a place with a strict network, how you can interface. Practising and figuring out will help to discover to most tricky questions of life. A short time later can portray a period or occasion when you felt loose and that each one turned out to be direct with the world, time when your reality was loaded up with a vibe of significance or when you encountered a vibe of dread.

\section{ESSENTIALS TO IMPROVE HEALTH THROUGH SPIRITUALITY}

Spirituality assess spiritual health which describes the state of mind one is involved. Employees working in the same environment with the same people and no change in their pedagogy will lead to creating monotony. But if the individual is involved with spiritual mindset then will discover hope, positive outlook, forgiveness, self-reputation, dedication, that means and motive in lifestyles, clean values, the experience of worth, peace, worship, prayer, and meditation. It has been observed that individuals not having association towards spirituality and consider atrophy as 'wasting away of the body or part of an organ' or as 'degeneration, decline, or decrease as from disuse. ${ }^{6}$ The three D's of Spiritual Atrophy 'degeneration, decline, or decrease' could have begun feeling of vacancy, anxiety, loss of meaning, self-judgment, self-condemnation, apathy, conflicting values, worried/annoyed/acting in haste and without rituals.

\section{FIVE TECHNIQUES TO GROW SPIRITUALLY AND ENHANCE NON SECULAR HEALTH}

1) Silence: Spiritual realities oftentimes are to be had the state of a still little voice that is difficult to focus on over the bedlam and disarray of a wild way of life. Set aside an ideal opportunity for isolation and reflection.

2) Discussion on Spirituality: Spiritual examinations frequently are to be had astounding organization and bundles. They wonder us. Cultivate a nonjudgmental mentality so you're friendly the profound measurement in any ways of life occasion - from hoeing the grass, to see a spot of destiny, from looking a swimming meet to considering the morning paper.

3) Probing and inquisitive: A mentality of dynamic looking builds your other options and your potential for spirituality focusing. Try not to close entryways sooner than you look at what's at the rear of them. For instance, the hint of hands may likewise be a solid focusing experience. A quiet retreat may reestablish your eagerness. Contemplation or yoga may likewise okay allow you to delight in serenity and harmony.

4) Willing to Forgive: Agony empowers us to practice inside the broadest inquiries of our being. It's far a deepener. Existence of a human being is to experience shallow ways of life. Permit yourself to sympathize with your agony totally, at that point ask, "What is it endeavouring to uncover me?"

5) Be cheerful: Play can be wonderful, freeing appreciates. It breeds unconstrained energy and gathering. When you make melody, move and chuckle, sing - however you play tune in for hints of the soul.

The representatives while comprehending the significance of non-common wellness, indications of Spiritual Health might be obvious because the astuteness and sustaining dating with self as well as other people will enhance and will build solid non-open cost framework with the expectation to develop and satisfy the intention of ways of life.

\section{PREPARATION FOR SPIRITUAL HEALTH}

Spiritual health could be considered as a way to remain energetic, mindful, vigilant and always enthusiastic to meet our life goals. When one is healthy by mind will lead to creating happiness around his world. Following are few remedies through which one if follows can become strong and develop a healthy state of mind:

- $\quad$ Take time for self-recharging

- Practice hallowed ceremonies

- Practice acknowledgement and non-judgment

- Keep the religion, supplicate; don't desert convictions in emergency 
- Embrace spine chiller. Permit yourself to concur with things that cannot be clarified

- Embrace the shadow, your dull perspective. Perceive and recognize it

- Forgiveness

- Put sympathy without hesitation

- Live up with pleasure

\section{EXPLORATION ON THE ROLE OF SPIRITUALITY IN HEALTH CARE}

The effect of Spirituality on wellbeing is an area of dynamic exploration immediately. Other than being concentrated by the method of doctors, it is concentrated by methods for therapists and various experts. The examination tends to fall under three prevalent territories: mortality, adapting and mending

All through records and across societies, Spirituality has been unequivocally identified with human services. Everything changed on occasions. Innovative advances and contemporary-day logical investigations revelations have little inquiry included exceptional improvement in drugs enabling to drag out and spare lives. ${ }^{7}$ Then again, those advanced procedures have moreover changed the essential objective of medications from a stressing, influenced individual orientated, the administration arranged model to a fix situated, illness orientated and innovative model.

Understanding the noteworthy capacity of Spirituality in human services and seeing its points of interest for patients, inside the current years, a few doctors are attempting to solidness their activity with Spirituality. ${ }^{8}$ Numerous medical clinics offer peaceful consideration and strict contributions to their victims and family units. More clinical specialists are rehearsing humane consideration getting the opportunity to serve the total man or lady, including their physical, enthusiastic, social and non-common pleasantly being. Exploration has demonstrated that Spirituality can advantage people's wellbeing and affect their mortality, adapting and reclamation.

\section{MORTALITY}

Exploration has demonstrated that individuals who have a step by step Spiritual practice tend to degree longer. Spirituality can upgrade pressure control, prompting better adapting abilities, quickened private force and more prominent social help. Some observational examinations recommend that oldsters who have typical profound practices commonly watch out for degree longer. Another examines focuses on a potential instrument. Expanded degrees are related with an all-encompassing pervasiveness of infirmity.

An examination takes a gander at concerning more established grown-ups demonstrated that individuals who nonmainstream in nature. The specialists speculated that nonmainstream responsibility may likewise improve strain control by methods for bestowing better ways of dealing with stress, more extravagant social help, and in this way the intensity of individual qualities and perspective.

\section{COPING/ADAPTING}

Spiritual exercise can help patients managing disease, throb and favoured ways of life stresses. It can assist them with owning an excellent viewpoint, to consider in the treatment plan, to think about reclamation and to make a far superior nature of presence. The examination has furthermore demonstrated that they consider more prone to have more prominent satisfaction, that implies, and reason throughout everyday life. They are bound to be searching for out those methods for their contamination. Spiritual solace and association can assist them in managing their disease and association. Even though the situation of throb medication is very indispensable, examines has demonstrated that unwinding, supplication, reflection, contact, and rubdown would all be able to help with hurt administration. In conclusion, Spirituality can direct relatives and buddies to address their adored one's contamination or passing.

Some exploration shows that the ones which are profound for the most part watch out for own a more phenomenal standpoint and a mile better fine of life. For instance, victims with deadly diseases discovered relief from their strict and profound standards had been more prominent happy with their lives, had been more joyful, and had considerably less hurt. Spirituality is a fundamental piece of the "existential territory" estimated in magnificent of-presence evaluations. Positive surveys on the ones estimate an important non-open life, accomplishment of presence objectives, and an encounter that life thereto point was advantageous associated with a fair remarkable of life for victims with unrivalled affliction.

Some exploration has likewise taken a gander at the situation of Spirituality concerning throb. One inspects indicated that non-common pleasantly being changed into identified with the power to delight in ways of life even inside the middle of signs, comprehensive of torment. Along these lines that Spirituality may likewise be an essential clinical objective.

Spiritual convictions can assist patients with managing illness and face biting the dust. At the point when mentioned what helped them adapt, they referenced non-mainstream convictions. Top issues have been discovering friendship and profound solace picked over things like development mandates, financial/money-related issues, and social concerns. Those that had been studied referred to a few profound consolations that could reassure them. The major typical strict consolations expressed have been convictions that they are most likely inside the caring nearness of God or a more powerful, that downfall wasn't the zenith however a section, which they may live to tell the story through their youths and relatives. 
Mourning is viewed as probably the best pressure. Guardians whose children had kicked the bucket of malignant growth found that they acquired encouragement from their non-mainstream convictions after their youngster's death toll. Those guardians had a higher physiologic and passionate modification. Furthermore, mother and father announced a fortifying in their strict commitment through the span of a year sooner than their infant's passing.

\section{RECOVERY/CONVALESCENCE}

Simply looking for fake treatment research, we will see that how ground-breaking conviction itself is routine. Patients are given fake treatment revel in gifts since they accepted that they were given genuine medication. They're prepared to spigot into their 'recalled prosperity' and feel higher. Spirituality can be a far more profound confidence in an option that could be more prominent than us and confidence in life itself. Profound practices can bring down nervousness, improve vanity, and upgrade substantial working. Patients visit their medical clinic treatment doctor with strain-related issues; Spirituality is as often as possible basic to bring down pressure and improves wellness. ${ }^{9}$ At last, humane and profound consideration can upgrade the influenced individual specialist seeking improving trust and rebuilding generously.

Spiritual commitment tends to boost restoration from distinct diseases. Individual's people who participated in religious sports with their beliefs had been work higher and progressed physical and intellectual functioning. They develop higher tiers of self-esteem and had much less tension and fewer health issues. Generally, human beings that don't fear the maximum quantity tend to possess higher fitness outcomes. ${ }^{10}$ Maybe spirituality permits human beings to strain much less, to forsaking and sleep at this moment. Associated with spirituality is that the electricity of believe and wonderful wondering. Spirituality is functionality to faucet into one's resource to heal shows that three additives make contributions to the effect of the patient-health practitioner courting: tremendous ideals and expectations on a part of the patients, positive ideals and expectations at a part of the physician or health care professional, and a sincere dating among the two parties. ${ }^{11}$

Explicit profound practices are appeared to decorate wellbeing impacts. Inside the began research at the impact of strict practices on wellbeing. Some people that rehearsed supernatural reflection moved toward him inside the Nineteen Sixties and mentioned him to exercise if contemplation had valuable wellness results. He found that ten to twenty minutes of contemplation multiple times everyday impacts in diminished digestion, diminished heartbeat, the diminished charge of respiratory, and more slow mind waves.

Meditation is a couple of things that every individual can rehearse regardless of their confidence, religion or Spiritual- ity. ${ }^{12}$ It can hose down the flight-or-battle system on your body, decline cholesterol, bring you rest, make greater dependability, and increment your real and mental country. Meditation as a method goes to acknowledge oneself totally, each from inside and outside. ${ }^{13}$ It likewise facilities to perceive who you are internal and the way you respond to what's outside. Most importantly, reflection is playing oneself inside the strict feeling of the planet observed that contemplation while through with full mindfulness and devotion it outcomes in wellness favours like reduce pressure, improves nervousness, decreases gloom, promotes passionate wellness, increases an inspirational point of view, increases reluctance, reduces age-related amnesia, generates consideration, helps to forestall addictions, improves rest, helps controlling hurt, decreases imperative sign, improves generally speaking physical and mental nation. ${ }^{8}$

Meditation helps to improve the wellbeing of the individual. Only requires firmness and loyalty. If it's followed with seriousness, there are steps to meditate which is as follows:

- Set your aim.

- Eliminate all reasons to prevent you from completing your contemplation repeating.

- Find a territory to sit effortlessly. It is regularly a seat, a pad or the floor.

- Don't get excessively comfortable. Remain quiet, anyway ready. Try not to rest off

- Keep your spine tall. Breathe in with the guide of moving your shoulders in your ears and breathe out through bringing down them.

- Close your eyes.

- Maintain a simple breath through and out your nose.

- Be influenced individual. Give time as a learning method.

- Observe your considerations without judgment.

- Don't communicate in or watch your psyche. Simply plunk down and be. Permit them to go as they get up.

- Shifts happen. Interruption is a piece of the methodology. Acknowledge it and hold.

- Move on the off chance that you need to. On the off chance that you have to scratch a tingle or shake your hands, move inside the roughage at that point come back to your breath.

\section{PERSPECTIVES AND CONCLUSION}

Healthcare is often considered with utmost compassionate care of the individuals who require special attention. Healthcare is quite identifying diseases and treating them with medication and surgery. People long for support. Helping involves caring, spending time, asking questions, talking about what's crucial and holding hand. "Man isn't destroyed by suffering; he's destroyed by suffering without meaning," said Viktor Frankl, psychiatrist, and Holocaust. Spirituality helps find this aiming to get through an illness, deal with pain 
and find healing and may support patients and their families through compassionate care. The spiritual state of mind individual care and listen can provide true support. The role of spirituality has been more widely known when supporting permanently ill and dying patients, but equivalent support should be there for those with less serious issues, treatable diseases, and chronic illness. Understanding spirituality can help to treat individual better. Spirituality may play a task in understanding diseases and decision to hunt mental support. Religious convictions also can play a task in deciding. ${ }^{.}$Spiritual practices are often a huge role in individual and their families coping. Therefore, spirituality plays an integral role in the holistic care of employees working in the organization.

To provide compassionate care following practices will facilitate to enhance the mental and physical well-being of employees like practice compassionate presence, provide a secure zone, hear their pain, fears, hopes and dreams, find their spiritual history, suggest spiritual practices (meditation, yoga) as appropriate, listening to know the holistic point of view including their body, mind and soul. ${ }^{3}$ Spiritual counsellors and spiritual leaders can initiate prayers or other religious activities to attach and motivate mentally and physically fit. Practising compassionate care and supporting spiritual aspects of healing encouraged sharing spiritual beliefs. Through this who feels weak within by applying compassionate care can get thinking about them "Healthy Hero" and initiate themselves to require care of their health and have interaction in spiritual practices to enhance your health and well-being. Spirituality helps to understand individual to go by the current. The majority go by the wind. Being everybody else comes without much effort. You were never meant to be everybody else. It also highlights that if a thousand people do something wrong, it doesn't make it right. Be your person. Remain as original as ever. Spirituality also clarifies that original who sticks to their game produce masterpieces. The midst of mediocrity, strive for superiority. Whilst everyone is lowly minded, think highly. The ordinariness that you see around is not for you to replicate but for you to challenge.

While working in an organization one should have a purpose. Success comes to those with success consciousness. If one's think failing, don't be surprised by the outcome. Ignite your passion and move ahead. Role of spirituality emphasis that never thinks of defeat, but that vision of across and never mind what anyone will say to distract. Keep moving until and unless reach to your goal. If the individual start working with a positive attitude will never allow a background to put back on the ground, make life count start breaking barriers, be inquisitive and persistent. No one could stop anyone.

\section{ACKNOWLEDGEMENT}

I express my sincere gratitude to Dr. Somesh Dhamija, Professor and Head of Department (UG) Institute of Business Management, GLA University, who took sincere care and provide support, motivation and encouragement like lighting a candle in my research and life. I sincerely thanks to Mr. Krishanveer Singh, Assistant Professor, Institute of Business Management for his consistent support to complete the research work. I thank the University Authorities for providing all the facilities and permission to complete my work without any delay.

\section{Conflict of Interest: Nil}

\section{Source of Funding: Self}

Ethical Clearance: Nil

\section{REFERENCES}

1. Dubhashi SP, Dalvi SD, Goel RB, Kadam NN, Kadam SN, Jadhav, PM. Gandhian Values in Health Science Education: Need for Global Revamp in Higher Education. Int J Curr Res Rev 2020;12(14):40.

2. Remen RN. Educating for Mission, Meaning, and Compassion. In book: The Heart of Learning: Spirituality in Education. 1999. 33-50.

3. Puchalski CM. The Role of Spirituality in Health Care. Proc (Bayl Univ Med Cent) 2001;14(4): 352-357.

4. Cole K, Daly A, Mak A. Good for the soul: The Relationship between Work, Wellbeing and Psychological Capital. J SocioEcon 2009;38(3):464-474.

5. Heintzman P. A Conceptual Model of Leisure and Spiritual Well-Being. J Park Recrea Adminis 2002;20:4.

6. Owen AD, Hayward RD, Koenig HG, Steffens DC. Payne ME. Religious Factors and Hippocampal Atrophy in Late Life. PLoS One 2011;6(3):e17006.

7. Ombati M. Rainmaking Rituals: Song and Dance for Climate Change in the Making of Livelihoods in Africa. Int J Modern Anthropol 2017;1(10):74-96.

8. Woods O. Sonic Spaces, Spiritual Bodies: The Affective Experience of the Roots Reggae Sound System. Transact Institute Br Geograp 2019;44(1):181-194.

9. Pesut B, Fowler M, Taylor EJ, Reimer Kirkham S, Sawatzky R. Conceptualising Spirituality and Religion for Healthcare. J Clin Nur 2008;17(21):2803-2810.

10. Cobb M, Puchalski CM, Rumbold B. The Future of Spirituality and Healthcare. 2012.

11. Benson H. Timeless Healing: The Power and Biology of Belief. New York:Simon and Schuster, 1996.

12. Shenwai RS, Tare KN. Integrated Approach towards Holistic Health: Current Trends and Future Scope. Int J Curr Res Rev 2017;9(7):11-14.

13. Dhamija A, Somesh D, Amit K. Wisdom of Yoga and Meditation: A Tight Rope to Walk Purushartha. J School Mgmt Ethics Spiritu 2017;10(1):117-125. 